\section{Anticancer activity of novel surface functionalized metal doped hydroxyapatite}

\author{
Saheli Pradhan ${ }^{1 *}$, Shouvik Mitra² and Arunava Goswami \\ ${ }^{1}$ Department of Botany, School of Applied and Basic Sciences, Career Point University, Kota, \\ Rajasthan- 325003, India
}

${ }^{2}$ AERU, Biological Sciences Division, Indian Statistical Institute, Kolkata-700108, India

\begin{abstract}
More Information
*Address for Correspondence: Saheli Pradhana, Department of Botany, School of Applied and Basic Sciences, Career Point University, Kota, Rajasthan- 325003, India, Email: saheli. pradhan@gmail.com

Submitted: 25 May 2020

Approved: 01 June 2020

Published: 03 June 2020

How to cite this article: Pradhan S, Mitra S, Goswami A. Anticancer activity of novel surface functionalized metal doped hydroxyapatite. Arch Pharm Pharma Sci. 2020; 4: 021-026.

DOI: 10.29328/journal.apps.1001023

Copyright: @ 2020 Pradhan S, et al. This is an open access article distributed under the Creative Commons Attribution License, which permits unrestricted use, distribution, and reproduction in any medium, provided the original work is properly cited.
\end{abstract}

Keywords: Hydroxyapatite; Nanocomposite; Surface grafting; Cytotoxicity; Cell viability

Check for updates

OPEN ACCESS

\section{Introduction}

Nanotechnology represents a new and enabling platform that promises to provide a range of innovative protocol for biomedical applications. Nanosized materials, such as nanoparticles, nanorods, nanowires, nanotubes and nanofiber have been explored in many biomedical applications because of their novel properties and multi functionality. Hydroxyapatite $\left[\mathrm{Ca}_{10}\left(\mathrm{PO}_{4}\right)_{6}(\mathrm{OH})_{2}\right](\mathrm{HAP})$ is an interesting biomaterial with potential orthopedic and dental applications due to its excellent biocompatibility, bioactivity and osteoconductivity [1-3]. It is however worth-mentioning that the application of pure HAP is limited due to its hardness and chemical stability. However in recent years HAp-polymer composite has gained importance with good biological and mechanical performances [4-6] along with dispersion in collagen matrix [7]. Sometimes nano-hydroxyapatite (nHAP) crystals are dispersed in suitable polymeric matrices [8-12] along with organophosphate and phosphonic acid based coupling agents [13-20] for various applications.

Transition metals are widely known for their in-vitro toxicity; however considerable efforts are being made towards their application in anticancer activity with their site specific targeting ability [21-23] to reduce infectious cancer cells. Mercury and its compounds are widely known for its high toxicities. Constant consumption of mercury (II) causes harmful disease like Minamata, Acrodynia and Hunter-Russell syndrome. However very low concentration of mercury delivery to cancer affected cell lines may act as alternative anticancer agent whose toxicity is expected to be less than that of Pt-compounds used as anti-cancer agent. Hydroxyapatite is bio-compatible and nontoxic in nature, therefore doping of mercury metal ion in low concentration will reduce the toxicity of metal ion to some extent. Mercury based compounds such as phenyl mercuric nitrate and phenyl mercuric acetate had been used as antimicrobial agents especially phenyl mercuric nitrate $[24,25]$ however no research reports are there of using mercury as anti-cancer agent. Oral administration of mercury based compounds causes toxicity due to their nonspecific binding towards proteins therefore our aim is to synthesize mercury doped nanocomposite into a biocompatible nanomaterial in order to remove nonspecific binding with proteins and avoid unexpected toxicity.

In our study a novel methodology has been developed to embed themercury ion into the nanoparticle of hydroxyapatite via sol-gel technique. In order to avoid the phagocytocis of 
the nanocomposite; the surface was functionalized by using phosphonomethyl iminodiacetic acid. Therefore grafting of carboxylic acid groups on to the surface of the particles render the nanocomposite to be more bio-compatible and stable dispersion in water or biological fluid. Mercury doped surface functionalized hydroxyapatite was then subjected to liver carcinoma cell line (Hep G2) and lung carcinoma fibroblast cell line (MRC 5) for in vitro cytotoxicological study. It is interesting to note that nanocomposite (MHAp) showed toxicity to the MRC 5 cell line whereas no toxicity was revealed towards Hep G2 cell line. Cytotoxicological study with mercury doped hydroxyapatite (MHAp) has not been reported till date to best of our knowledge. Therefore we were motivated to develop an unique synthesis of mercury doped surface functionalized nanoparticle of hydroxyapatite (nMHAP) and their applications as anti-cancer agents. The material has two major advantages:

(1) The precursors used in the whole process are inexpensive and easy to synthesize.

(2) Nanoparticle of MHAp has site specific anticancer activity towards lung carcinoma fibroblast cell line (MRC 5) whereas no toxicity was observed towards liver carcinoma cell line (Hep G2). Therefore reduction of toxicity in the nanocomposite switch the nanocomposite as anticancer agent towards lung fibroblast cell line.

\section{Materials and methods}

\section{Chemicals}

Calcium nitrate (99\%), diammonium hydrogen phosphate (DAHP) (99\%), mercuric chloride were obtained from E. Merck (India). Triethanolamine (TEA) (98\%) and phosphonomethyl iminodiacetic acid were purchased from Sigma-Aldrich. Ammonia solution (25\%), ammonium chloride (98\%), and ethanol were also obtained from E. Merck (India). All the chemicals were of analytical grades and used without further purification. Milli-Q grade water (Sartorious Stedim Biotech) was used for all bio-assay with its conductivity less than $0.1 \mu \mathrm{S} \mathrm{cm}^{-1}$.

\section{Cell lines}

MRC 5 and HepG2 cell lines were purchased from ATCC (catalog no. CCL-171and HB-8065). All cultures were maintained in a phenol red free culture medium DMEM/ F12 (Dulbecco's modified essential medium/Ham's 12 nutrient mixture, Gibco), supplemented with $5 \%(\mathrm{v} / \mathrm{v})$ fetal calf serum (JS Bioscience, Australia), and 1\% (v/v) antibiotic (2 mM L-glutamine, $100 \mathrm{U} / \mathrm{mL}$ Penicillin and 0.1 $\mathrm{mg} / \mathrm{mL}$ Streptomycin; Gibco). Cultured cells were kept at $37^{\circ} \mathrm{C}$ in a humidified $5 \% \mathrm{CO}_{2}$ incubator. Once the cells reached confluence, the culture medium was removed from the flask and the cells were rinsed three times with sterile HBSS (Hank's Balanced Salt Solution, Gibco). The confluent cell layers were enzymatically removed, using Trypsin/ EDTA (Gibco, USA), and re-suspended in culture medium. Cell viability was assessed by vital staining with trypan blue $(0.4 \%(\mathrm{w} / \mathrm{v})$; Sigma, USA), and cell number was determined using an optical microscope (Carl Zeiss).

\section{Experimental section}

\section{Synthesis of mercury doped nano hydroxyapatite}

Mercury doped hydroxyapatite was synthesized by modification of a previously reported method [14]. In brief, stock solution of $0.5(\mathrm{M})$ of calcium nitrate $\mathrm{Ca}\left(\mathrm{NO}_{3}\right)_{2} \cdot 4 \mathrm{H}_{2} \mathrm{O}$, $0.5(\mathrm{M})$ of diammonium hydrogen phosphate $(\mathrm{NH} 4)_{2} \mathrm{HPO}_{4}$ (DAHP) and 0.01 (M) of mercuric chloride solution was prepared in distilled water. Calcium nitrate and diammonium hydrogen phosphate solution was taken in such an amount that the net atomic ratio of $\mathrm{Ca}: \mathrm{P}$ was maintained at 1.67 . Triethanolamine (TEA) was used in conjugation with calcium nitrate as the size controlling agent during its precipitation. The final $\mathrm{pH}$ of the reaction mixture of calcium nitrate and diammonium hydrogen phosphate solution was maintained throughout at $~ 11-12$ using dilute ammonia. DAHP solution and $10 \mathrm{ml}$ of $0.01(\mathrm{M})$ mercuric chloride solutions was added drop wise simultaneously to the mixture of calcium nitrate and triethanolamine and stirred vigorously at ambient temperature with the help of a mechanical stirrer with 3000 rpm. The reaction mixture was allowed to stir for about 6 hours and produced a gelatinous precipitate. The precipitate was separated by centrifugation at $4000 \mathrm{rpm}$ for 15 minutes. The precipitate was washed thoroughly with water and ethanolic ammonium chloride to remove excess of TEA. Finally the obtained product was dried at $90^{\circ} \mathrm{C}$ for 15 hours.

\section{Grafting of carboxylic acid on the surface}

Carboxylic acid functionalized mercury doped hydroxyapatite (nMHAP) was synthesized by using phosphonomethyl iminodiacetic acid (PMIDA). In brief, about $500 \mathrm{mg}$ of the nanocomposite was taken in $25 \mathrm{ml}$ of distilled water and kept in a sonication bath for about 45 minutes until a well dispersed solution was obtained. To this well dispersed sample solution aqueous alkaline solution of PMIDA was added drop wise maintaining the molar proportion of 1:1, alkaline pH 9 was maintained throughout the addition process. The reaction mixture was allowed to stir for 6 hours; finally the product was separated by centrifugation at $4000 \mathrm{rpm}$ for 15 minutes. The product was washed with distilled water for several times to remove excess of PMIDA and dried at a temperature of $60{ }^{\circ} \mathrm{C}$. Carboxylic acid grafted nanocomposite was very stable in aqueous dispersion; this functionalized composite was used for bio-assay.

\section{Characterization}

Morphology of the nanocomposite was investigated by using SUPRA 40 Field Emission Scanning Electron Microscope 
of Carl Zeiss with acceleration voltage of $5.0 \mathrm{kV}$. For FESEM sample preparation aqueous solution of the test sample was put on a properly cleaned glass slide followed by spin coating. XRD of the sample was carried out in Bruker D8 instrument applying a primary beam monochromator to select the K $\alpha 1$ component of the employed copper radiation (wavelength of $1.54056 \AA$ ). The samples for XRD were prepared by deposition of the samples on glass slide followed by drying in air. FTIR spectra were recorded in Perkin-Elmer spectrum 100. Prior to FTIR measurements the samples were ground with $\mathrm{KBr}$ (spectroscopic grade) and pressed to pellets. Surface morphology of mercury doped nano hydroxyapatite (nMHAP) was obtained by Atomic Force Microscpe NTEGRA (TS 150) in tapping mode. Hydrodynamic radius of the sample and particle size distribution (PSD) was measured by using Dynamic Light Scattering (DLS) in a particle size analyzer (90 Plus, Brookhaven Instrument Corporation, USA). Particle size was confirmed by using HRTEM of Phillips CM 200 at an operational voltage of $200 \mathrm{kV}$. For HRTEM micrograph a well dispersed aqueous solution of the sample was put into uniform copper coated TEM grid and well dried in air. For toxicological studies, OD of the samples was measured by using Shimadzu absorption spectrophotometer (Model No. 1700).

\section{Cytotoxicity testing of MRC 5 and HepG2 cell lines by WST assay}

This assay was based on enzymatic conversion of the tetrazolium salt WST-1 to formazan by cellular mitochondrial dehydrogenases present in viable cells. Briefly, cultured cells were diluted to 30,000 cells/ ml using an 8-channel pipette and then $100 \mu \mathrm{l}$ of well-mixed cell culture was added to each well except the last column on a 96-well plate. The plates were incubated in $\mathrm{CO}_{2}$ incubator overnight. Then nMHAP was added at $25,50,100,200$ ppm concentration respectively in different well with positive (cell in media without any chemical treatment) and negative control (cell in media with EDTA treatment) by using 8-channel pipette dispenser. After incubation for 72 hours, WST-1 proliferation reagent (Roche) was added to the cells ( $10 \mu \mathrm{l}$ per well) and incubation was continued for 4 hours at $37^{\circ} \mathrm{C}$. Plates were checked visually by comparing the colours of wells filled with treated cells (pink) and untreated cells showed orange colour. When a clear difference was seen by naked eye, results were checked by spectrophotometer at $490 \mathrm{~nm}$.

\section{Dose response curves of in-vitro cytotoxicity data}

Percentage of viable cells at different concentrations of nMHAP and in control wells gave different optical density value in spectrophometer. Dose response curves were plotted graphically from these plotted absorbance data.

\section{Results and discussion}

Particle size distributions (PSD) and hydrodynamic radius of synthesized mercury doped nano hydroxyapatite (nMHAP) was recorded from Dynamic Light Scattering by using a laser light $(\lambda=660 \mathrm{~nm})$ scattered at an angle $\theta=90^{\circ}$ at $25^{\circ}$, placing the dispersion in a glass cuvette. A well diluted sample solution in milli-Q water was taken in a test tube and sonicated for 30 minutes in a sonication bath (Branson). After settling for 10 minutes the solution was again diluted with same ratio of milli-Q water and measurements were performed after sonication of the solution for 30 minutes. The average size was found to be $400 \mathrm{~nm}$ with poly dispersity index 0.255 . DLS results were quite higher compared to actual size of the nanocomposite as it showed its hydrodynamic radius.

Figure 1a,b represented the low and high resolution FESEM image of the nMHAP. It revealed that the functionalized doped nanocomposite was completely rod shaped in nature, the inset image showed the individual rod like structure. The morphology was quite distinct however mixture of morphologies was not obtained in our micrograph.

Crystalline nature of the sample was determined by

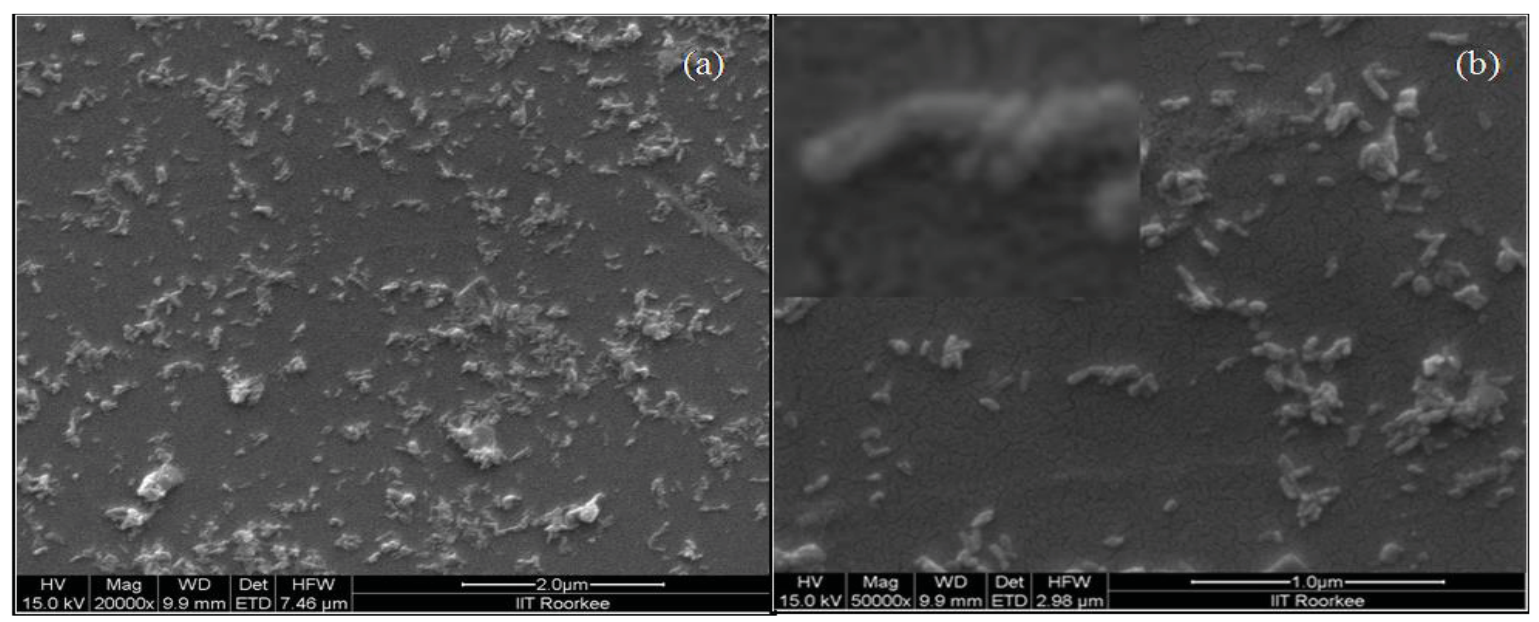

Figure 1: (a) FESEM image of mercury doped hydroxyapatite, (b) High resolution FESEM image of mercury doped hydroxyapatite; inset showing the rod shaped nature of the nanocomposite. 
XRD, prior to X-ray irradiation the samples were deposited on properly cleaned glass slides and dried well. Figure $2 \mathrm{a}$ demonstrated the XRD pattern of pure nano hydroxyapatite without any surface modification which showed 12 clearly visible peaks. The peaks obtained at $2 \theta=25.92^{\circ}, 28.09{ }^{\circ}$,

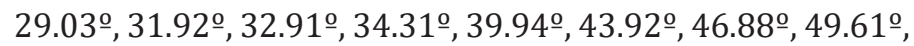
$53.44^{\circ}, 64.20^{\circ}$ could be indexed to (002), (102), (210), (211), (300), (202), (130), (113), (222), (213), (004) and (323) diffraction planes of hydroxyapatite with a hexagonal structure [JCPDS card no. 74-0566] [26]. Whereas for nMHAP the peaks were almost unshifted with $2 \theta=25.92^{\circ}$,

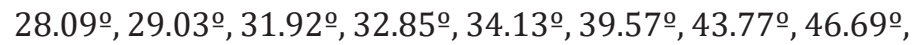
$49.43^{\circ}, 53.25^{\circ}$ and $64.01^{\circ}$ indicating the same diffraction plane in figure $2 \mathrm{~b}$. Therefore the fabricated substrate possessed crystalline structure with doping of mercury ion in its amorphous form in to the crystalline structure of hydroxyapatite keeping the crystalline structure of native hydroxyapatite unchanged.

Successful surface functionalization on mercury doped hydroxyapatite was further confirmed by FTIR spectroscopy. FTIR spectra showed 7 characteristic peaks shown in figure 3 , among which $3436 \mathrm{~cm}^{-1}$ was for the $\mathrm{O}-\mathrm{H}$ stretching. The peak obtained at $2914 \mathrm{~cm}^{-1}$ signified $\mathrm{C}$-H stretching and the $\mathrm{C}=0$ stretching frequency for carboxylic acid appeared at $1650 \mathrm{~cm}^{-1}$. The peak appeared at $1380 \mathrm{~cm}^{-1}$ and $1106 \mathrm{~cm}^{-1}$ was for the characteristic of $\mathrm{C}-\mathrm{O}-\mathrm{H}$ bending and $\mathrm{C}-\mathrm{N}$ stretching respectively. However the lower peak at $614 \mathrm{~cm}^{-1}$ and 1036 $\mathrm{cm}^{-1}$ was attributed to $\mathrm{PO}_{4}^{3-}$ and $\mathrm{P}-\mathrm{OH}$ group respectively [26].

The surface morphology was obtained by atomic force microscopy which revealed the rod structure of the fabricated nanocomposite with average size $40 \mathrm{~nm}$ with average roughness of $9.44 \mathrm{~nm}$. Figure $4 \mathrm{a}$ showed the AFM image and figure $4 \mathrm{~b}$ showed its 3D diagram of surface morphology along with the histogram.

Appropriate particle size was determined by using high resolution transmission electron microscopy. Figure 5 showed the HRTEM micrograph which revealed that the fabricated Hg doped nanohydroxyapatite particles were rod shaped in nature. The average size of the particles ranged from $20 \mathrm{~nm}$ to $50 \mathrm{~nm}$. The particles were distinctly visible and did not undergo agglomeration which also satisfied AFM results. Crystalline structure of the particle was further confirmed by SAED pattern (Figure 6). Chemical composition was confirmed by EDAX analysis, which showed that $\mathrm{Ca}, \mathrm{P}$, $\mathrm{O}$ and $\mathrm{Hg}$ were present as the major chemical component (shown in supplementary information S1) with nearly $23 \%$ of mercury present in the sample.

Exposure to nMHAP nanoparticle showed cytotoxic responses to MRC 5 cell line. In this case $76.44 \%, 71.87 \%$, $58.39 \%$ and $34.98 \%$ cells were alive after 72 hours of incubation with 25, 50, 100 and 200 ppm concentration of
nMHAP respectively shown in figure 7a. In case of nMHAP treatment at these same dosages on HepG2 cell line, almost all cells were alive after 72 hours of the experiment, which means nMHAP is nearly nontoxic to HepG2 cells (Figure $7 b)$. Though, mercury was itself toxic in nature, a specific carcinoma cell lines were affected by the nMHAP treatment. Moreover, doping with a bio-compatible constituent might have reduced its toxicity effectively. This unique result showed

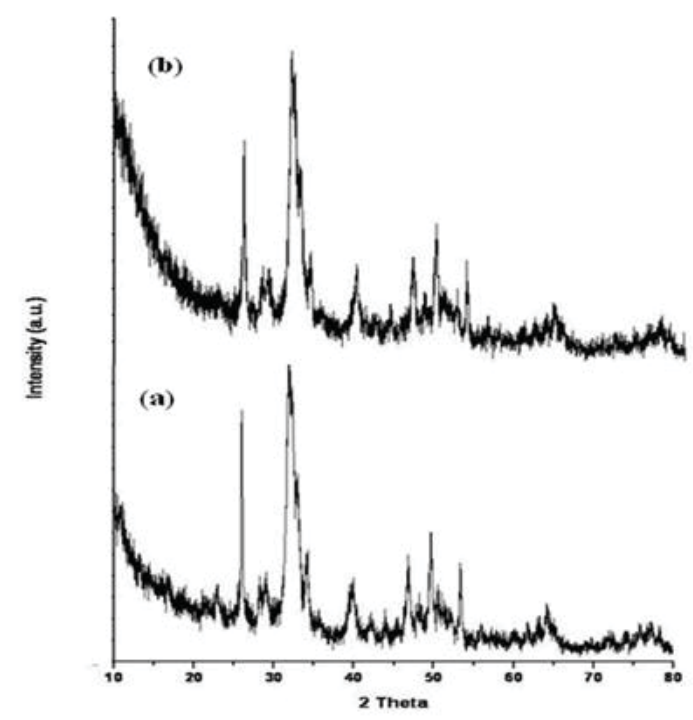

Figure 2: XRD pattern of (a) Hydroxyapatite, (b) Mercury doped hydroxyapatite.

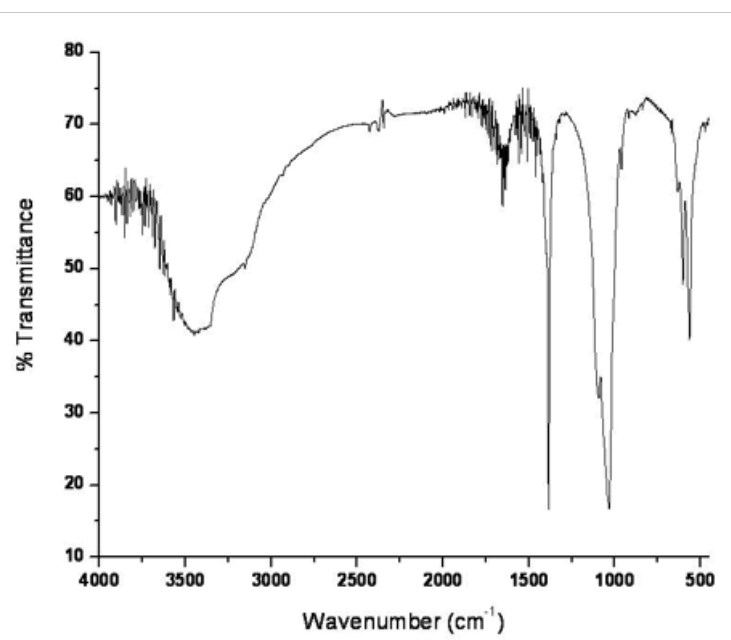

Figure 3: FTIR spectra of surface functionalized mercury doped hydroxyapatite.

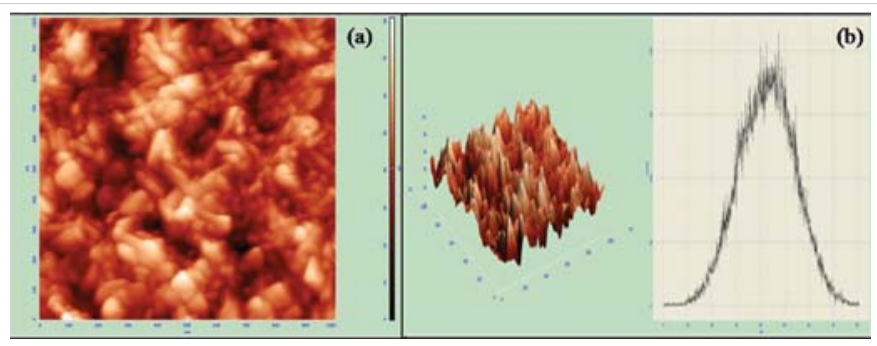

Figure 4: (a) AFM image of mercury doped hydroxyapatite, (b) 3D AFM image and histogram. 

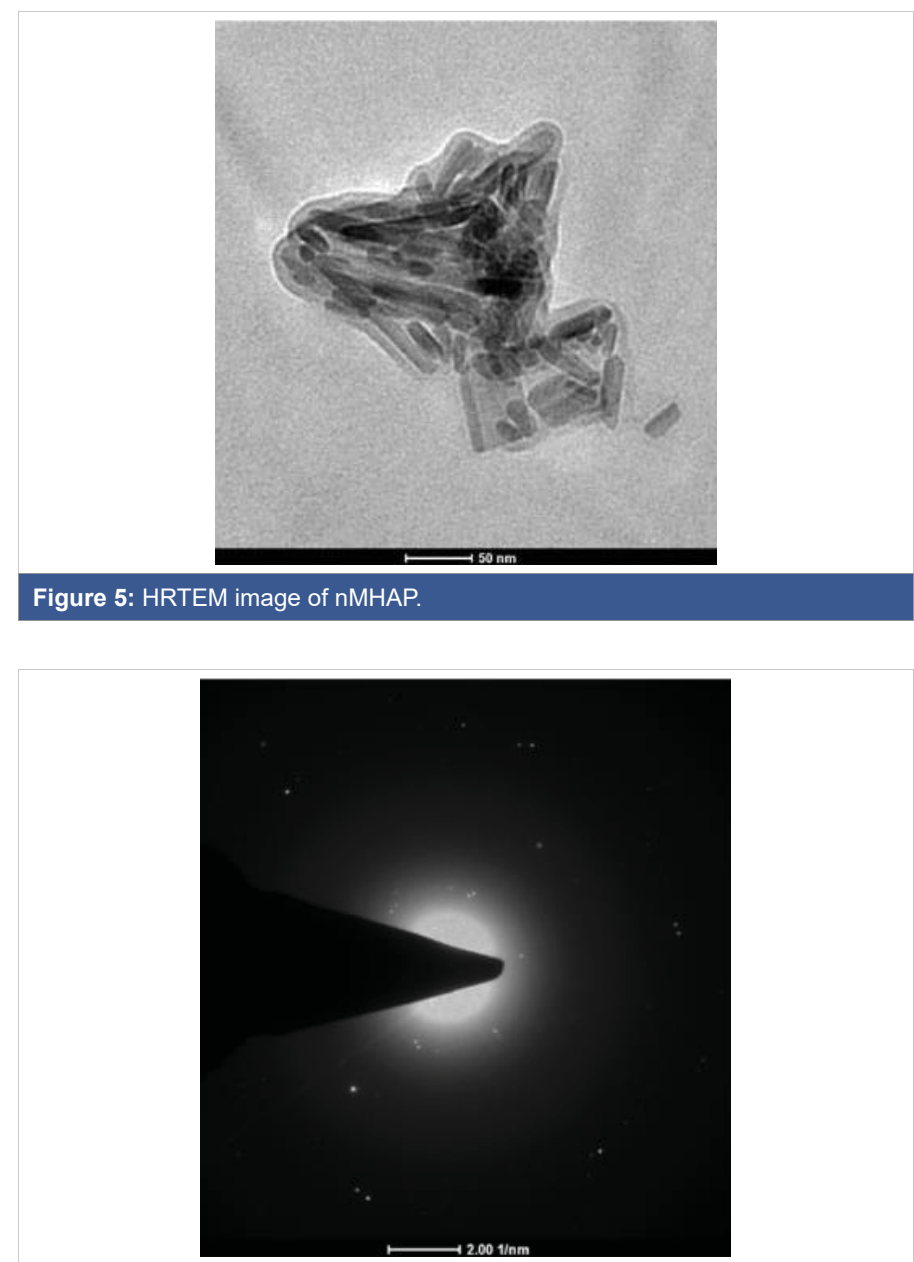

Figure 6: SAED pattern of mercury doped hydroxyapatite.

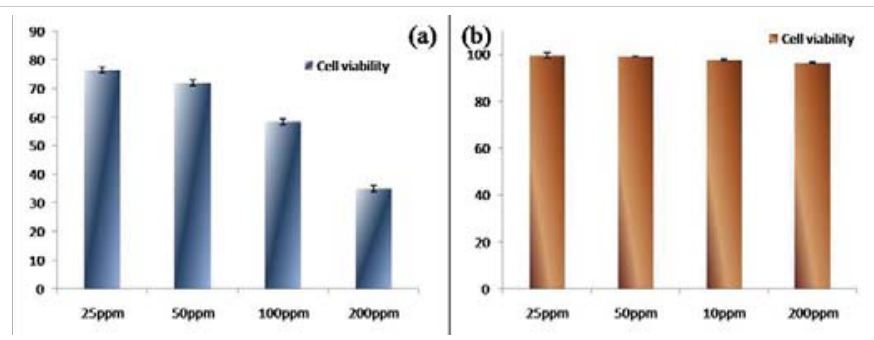

Figure 7: Toxicological study on (a) MRC 5 cell lines, (b) Hep G2 cell lines.

that cytotoxicity of a toxic component like mercury could be reduced to some extent by doping with a bio-compatible component. Cytotoxicity induced by nanoparticles has been attributed to a variety of mechanisms, which includes particle-induced apoptosis by up-regulation of Fas on the cell membrane, membrane damage and by intracellular effects associated with particle endocytosis. The upregulation of Fas indicates a link to anticancer activity [27]. This is certainly speculative at this point and needs further careful studies, especially to explain the selective toxicity to cancer cells.

\section{Conclusion}

This manuscript describes the doping of toxic mercury ions on to bio-compatible hydroxylapatite. Hydroxylapatite was synthesized by a novel sol-gel method comprising

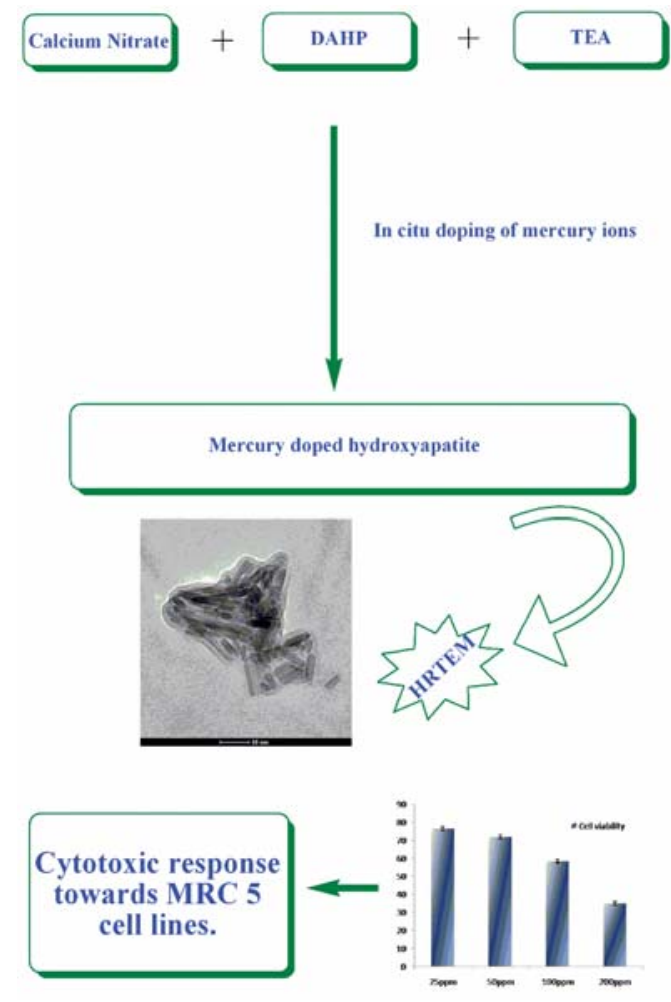

Hghap TOC.

mercury ion in situ. The nanocomposite was functionalized by grafting of carboxylic acid on to its surface by using PMIDA which was confirmed by FTIR study. High resolution TEM image showed that the particles were uniformly rod shaped with their size ranging from $20 \mathrm{~nm}$ to $50 \mathrm{~nm}$. This nanoconposite showed unique site specific action on human fibroblast cell line MRC 5. Though nMHAP is toxic to MRC 5 cells, it showed no toxicity against liver carcinoma cell line HepG2. LD-50 for MRC 5 was found to be 133.13 ppm by regression method.

Though mercury was toxic in nature, it did not show toxicity against HepG2 cells. Liver is the organ for storage of harmful substances and removal of toxins. The popular chemotherapeutic drugs cause major damages to liver cells. As this nMHAP is nontoxic to hepatic cells, it may be the drug of choice for treating site specific carcinoma with minimum side effect.

\section{Acknowledgement}

We would like to thank ISI plan project for collaborative efforts and their generous financial support.

\section{References}

1. Kothapalli CR, Shaw MT, Wei M. Biodegradable HA-PLA Porous Scaffolds: Effect of Nano-Sized Filler Content on Composite Properties. Acta Biomater. 2005; 1: 653-662.

PubMed: https://pubmed.ncbi.nlm.nih.gov/16701846/

2. Wang H, LiY, Zuo Y, Li J, Ma S, et al. Biocompatibility and osteogenesis of biomimetic nano-hydroxyapatite/polyamide composite scaffolds for bone tissue engineering. Biomaterials. 2007; 28: 3338-3348. PubMed: https://www.ncbi.nlm.nih.gov/pubmed/17481726 
3. Pramanik N, Tarafdar A, Pramanik P. Capping agent-assisted synthesis of nanosized hydroxyapatite: Comparative studies of their physicochemical properties. J Mater Process Technol. 2007; 184: 131-138.

4. Wan YZ, Huang Y, Yuan CD, Raman S, Zhu Y, et al. Biomimetic synthesis of hydroxyapatite/bacterial cellulose nanocomposites for biomedical applications. Mater Sci Eng C. 2007; 27: 855-864.

5. Marques AP, Reis RL. Hydroxyapatite reinforcement of different starch-based polymers affects osteoblast-like cells adhesion/ spreading and proliferation. Mater Sci Eng C. 2005; 25: 215-229.

6. Converse GL, Yue W, Roeder RK. Processing the tensile properties of hydroxyapatite-whisker-reinforced polyetheretherketone. Biomaterials. 2007; 28: 927-935.

PubMed: https://www.ncbi.nlm.nih.gov/pubmed/17113143

7. Bacon GE, Bacon PJ, Griffiths RK. Neutron diffraction studies of lumbar vertebrae. J Anat. 1979; 128: 277-283.

PubMed: https://www.ncbi.nlm.nih.gov/pubmed/438090

8. Xu X, Chen X, Liu A, Hong Z, Jing X. Electrospun poly(L-lactide)grafted hydroxyapatite/poly(L-lactide) nanocomposite fibers. Eur. Polym. J. 2007; 43: 3187-3196.

9. Chen M, Tan J, Lian Y, Liu D. Preparation of Gelatin coated hydroxyapatite nanorods and the stability of its aqueous colloidal. Appl Surf Sci. 2008; 254: 2730-2735.

10. Kim S, Kim SS, Lee SH, Ahn SE, Gwak SJ, et al. In vivo bone formation from human embryonic stem cell-derived osteogenic cells in poly(D,L-lactic-co-glycolic acid)/hydroxyapatite composite scaffolds. Biomaterials 2008; 29: 1043-1053.

PubMed: https://www.ncbi.nlm.nih.gov/pubmed/18023477

11. W OC, Hull JR. Surface modification of nanophase hydroxyapatite with chitosan. Mater Sci Eng C. 2008; 28: 434-437.

12. Boanini E, Torricelli P, Gazzano M, Giardino R, Bigi A. Nanocomposites of hydroxyapatite with aspartic acid and glutamic acid and their interaction with osteoblast-like cells. Biomaterials. 2006; 27: 4428-4433. PubMed: https://www.ncbi.nlm.nih.gov/pubmed/16682075

13. Mohapatra S, Pramanik N, Ghosh SK, Pramanik P. Design of Superparamagnetic Iron Oxide Nanoparticle for Purification of Recombinant Proteins. J Nanosci Nanotechnol. 2006; 6 : 823-829.

14. Pramanik N, Mohapatra S, Pramanik P, Bhargava P. Processing and Properties of Nano-Hydroxyapatite(n-HAp)/ Poly(Ethylene-Co-Acrylic Acid)(EAA) Composite Using a Phosphonic Acid Coupling Agent for Orthopedic Applications. J Am Ceram Soc. 2007; 90: 369-375.

15. Ikemura K, Tay FR, Nishiyama N, Pashley DH, Endo T. Design of new phosphonic acid monomers for dental adhesives--synthesis of (meth) acryloxyalkyl 3-phosphonopropionates and evaluation of their adhesion-promoting functions. Dent Mater J. 2006; 25: 566-575. PubMed: https://www.ncbi.nlm.nih.gov/pubmed/17076329
16. Andrea SCD, Fadeev AY. Covalent Surface Modification of Calcium Hydroxyapatite Using n-Alkyl- and n-Fluoroalkylphosphonic Acids. Langmuir. 2003; 19: 7904-7910.

17. Nancollas GH, Tang R, Phipps RJ, Henneman Z, Gulde S,et al. Novel insights into actions of bisphosphonates on bone: Differences in interactions with hydroxyapatite. Bone. 2006; 38: 617-627.

PubMed: https://pubmed.ncbi.nlm.nih.gov/16046206

18. Ganguli A, Steward C, Butler SL, Philips GJ, Meikle ST, et al. Bacterial adhesion to bisphosphonate coated hydroxyapatite. J Mater Sci Mater Med. 2005; $16:$ 283-287.

PubMed: https://www.ncbi.nlm.nih.gov/pubmed/15803271

19. Boanini E, Torricelli P, Gazzano M, Giardino R, Bigi A. Alendronatehydroxyapatite nanocomposites and their interaction with osteoclasts and osteoblast-like cells. Biomaterials. 2008; $29: 790-796$.

PubMed: https://www.ncbi.nlm.nih.gov/pubmed/18022226

20. Leu CT, Luegmayr E, Freedman LP, Rodan GA, Reszka AA. Relative binding affinities of bisphosphonates for human bone and relationship to antiresorptive efficacy. Bone. 2006; 38: 628-636.

PubMed: https://pubmed.ncbi.nlm.nih.gov/16185944

21. Kim SH, Jeong JH, Chun KW, Park TG. Target-Specific Cellular Uptake of PLGA Nanoparticles Coated with Poly(l-lysine)-Poly(ethylene glycol)-Folate Conjugate. Langmuir. 2005; 21: 8852-8857.

PubMed: https://www.ncbi.nlm.nih.gov/pubmed/16142970

22. Ennis BW, Lippman ME, Dickson RB. The EGF receptor system as a target for antitumor therapy. Cancer Invest. 1991; 9: 553-562.

PubMed: https://www.ncbi.nlm.nih.gov/pubmed/1933488

23. Leamon CP, Reddy JA, Vetzel M, Dorton R, Westrick E, et al. Folate Targeting Enables Durable and Specific Antitumor Responses from a Therapeutically Null Tubulysin B Analogue. Cancer Res. 2008; 68: 9839-9844.

PubMed: https://www.ncbi.nlm.nih.gov/pubmed/19047164

24. Hart A. Antibacterial activity of phenylmercuric nitrate in zinc sulphate and adrenaline eye drops. J Pharm Pharmacol. 1973: 25: 507-508.

PubMed: https://www.ncbi.nlm.nih.gov/pubmed/4146598

25. Barr FS, Collins GF, Moore GW. Evaluation of the antimicrobial activity of a phenylmercuric acetate-bithionol topical spray. Vet Med Small Anim Clin. 1966; 11: 1083.

26. Pramanik N, Mohapatra S, Bhargava P, Pramanik P. Chemical synthesis and characterization of hydroxyapatite (HAp)-poly (ethylene co vinyl alcohol) (EVA) nanocomposite using a phosphonicacid coupling agent for orthopedic applications. Mater Sci Eng C. 2009: 29: $228-236$.

27. Owen-Szcaub LB. Soluble Fas and Cancer. Clin. Cancer Res. 2001: 7: 1108-1109. 